\title{
On the basic phenomenon of soil-structure interaction on the free vibration response of beams: application to railway bridges
}

\author{
A. Doménech ${ }^{\mathrm{a}, *}$, M.D. Martínez-Rodrigo ${ }^{\mathrm{a}}$, A. Romero ${ }^{\mathrm{b}}$, P. Galvín ${ }^{\mathrm{b}}$ \\ ${ }^{a}$ Universitat Jaume I, Department of Mechanical Engineering and Construction, Avda. Sos Baynat s/n, 12071 Castellón, Spain \\ ${ }^{b}$ Escuela Técnica Superior de Ingeniería, Universidad de Sevilla, Camino de los Descubrimientos s/n, 41092 Sevilla, Spain
}

\begin{abstract}
The dynamic transverse response of beam type bridges under railway traffic is addressed in this contribution. In particular, how soil-structure interaction may affect the critical or resonant speeds and the associated vibratory amplitudes is evaluated in detail. Resonance in beams, due to the circulation of equidistant loads, is highly influenced by the free vibration response that every single load leaves after traversing the structure. On this basis a numerical investigation is carried out analysing the effects of the wave propagation problem on the free vibration response of simply-supported beams in a wide range of travelling speeds. To this end a coupled three-dimensional boundary element-finite element model formulated in the time domain is used to reproduce the soil and structural behaviour, respectively. A catalogue of bridge deck typologies is defined, covering lengths, associated linear masses and fundamental frequencies that may experience high levels of transverse accelerations under resonant conditions, for nowadays existing trains and design speeds. Lengths ranging from 12.5 to $25 \mathrm{~m}$ are evaluated, along with fundamental frequencies covering most common typologies. A homogeneous soil is considered with shear wave speeds in the interval 150 to $365 \mathrm{~m} / \mathrm{s}$. From the single load free vibration parametric analysis conclusions are derived regarding the conditions of maximum free vibration and cancellation of the deck response. These conclusions are used afterwards to justify how resonant amplitudes of the bridge under the circulation of railway convoys may be affected by the soil properties, leading to substantially amplified responses or to almost imperceptible ones, and a numerical example is included to show the aforementioned situations.
\end{abstract}

Keywords: Soil-structure interaction, moving loads, resonance, cancellation, railway bridges, BEM-FEM model

\section{Introduction}

The development of high speed technologies has powered railway transport as a key element in the accessibility of the territory in many countries. As a consequence of modern railway transportation systems becoming faster and heavier, railway infrastructures are subjected to more and more demanding specifications in order to guarantee structural integrity and travelling comfort. Railway bridges have received special attention in this context as the periodic nature of axle loads may induce important vibration levels in the super-structures, particularly under resonant conditions that may become apparent at high speeds [1-3]. Especially critical in this regard are short-to-medium span bridges composed by simply-supported (SS) decks with usually low associated masses (see Figure 1), which may experience high transverse acceleration levels in these situations $[1,4]$. This problem aggravates for low structural damping levels, typical in the aforementioned constructions [1]. Resonance in railway bridges may lead to adverse consequences such as ballast destabilization, general degradation of the track and a raise in the maintenance costs of the line $[1,4]$. Even if these situations do not inherently lead to the failure of the structures, they might certainly cause them to reduce their serviceability.

\footnotetext{
${ }^{*}$ Corresponding author. Tel.: +34 964387472; fax: +34964728106

Email address: domeneca@uji.es (A. Doménech)
}

In this context, the vibratory behaviour of railway bridges has received substantial attention by the engineer and scientific community in the last decades [5]. A classical and simple approach to the problem of vehicles crossing over bridges is the analysis of beams under moving loads at constant speeds. This model is appropriate when the deck vertical response is mainly governed by its longitudinal bending modes and when the interest focuses on the structure behaviour, and not the vehicle's, as vehicle-structure interaction is disregarded. Numerous works are reported in the literature in this regard [5-10].

Resonance in SS beams or bridges takes place when the excitation period of the axles, i. e., the ratio between a characteristic, or many times repeated, distance and the train speed is a multiple of one natural period of the structure. When this occurs, the free vibration oscillations induced on the structure by every load accumulate, and the transverse response of the bridge progressively increases, leading to a substantial amplification if the number of axles is sufficient. In short to medium span bridges with nowadays maximum train speeds, the characteristic distance associated with detrimental levels of transverse accelerations due to resonance usually corresponds to the length of the passengers' coaches. Therefore, the amplification of the transverse response of beams or bridges at resonance depends both on the periodicity of the loads and on the amplitude of the free vibrations left by every single load. Under ideal SS con- 
ditions and in the absence of damping, the amplification of the free vibrations left by every load depends on the ratio between the structural periods and the travelling time of the load. As indicated in [11] depending on this ratio the beam may experience substantial levels of free vibrations (maximum free vibrations) or these may practically cancel (cancellation of free vibrations).
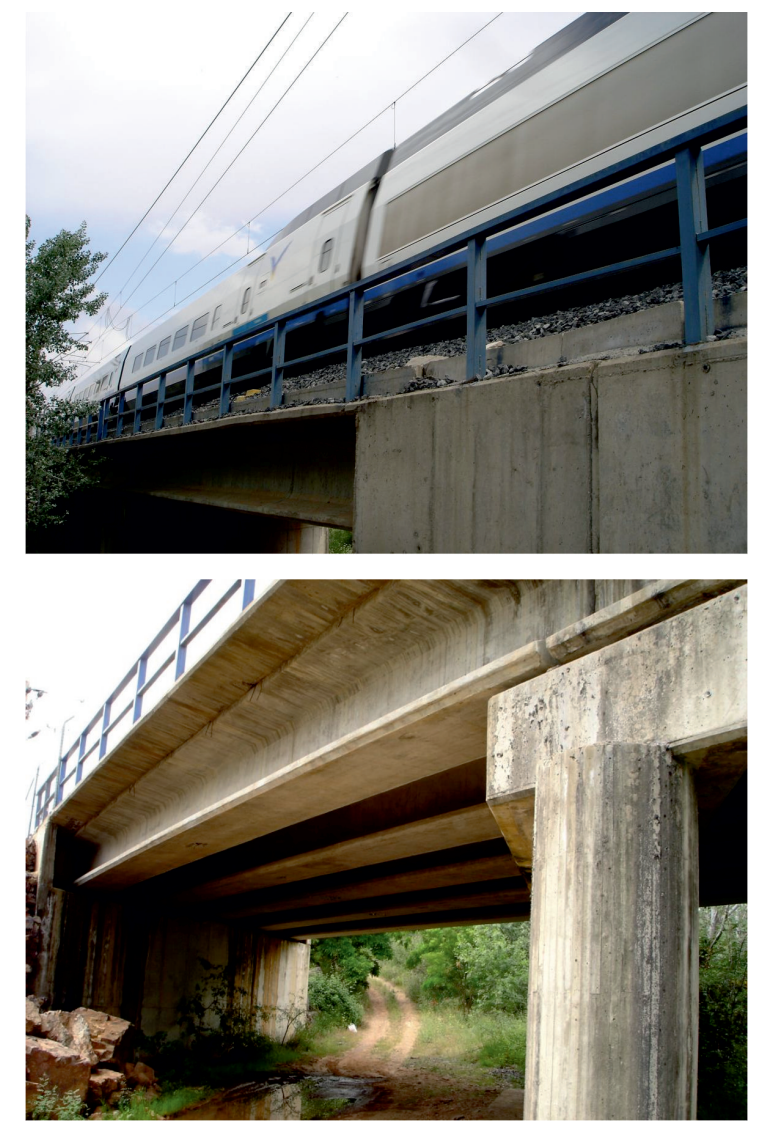

Figure 1: Railway bridge in Spanish high speed line composed by short simply-supported bays

The phenomena of resonance and cancellation experienced by beams under the circulation of moving loads has been studied by several researchers. In the works of [12] the parameters governing resonance of SS beams subjected to different periodic moving systems are presented and analysed. In [13] span to car length optimal ratios are proposed in order to suppress the first resonance of the fundamental mode of SS beams. A few years later in [14] approximate formulas for predicting the amplitudes for the maximum deflection, bending moment and transverse acceleration of SS beams subjected to first resonance of the fundamental mode are presented. In [15] the authors investigate the relevance of the second bending mode contribution for the determination of the maximum displacement and acceleration responses in high-speed bridges using beam models. In [9] the cumulative effect of free vibrations on the response of beams with classical boundary conditions under moving loads is investigated in detail. Approximate expressions for the maximum deflection and acceleration of the structures are provided based on a response spectrum of the train. The au- thors in [16] investigate the acceleration at resonance in simple beams and the contribution to the maximum response of modes higher than the fundamental one. They conclude that in the presence of damping the contribution of higher modes to the acceleration response can be neglected as it quickly damps out. Among the most recent publications [11] analyses the maximum free vibration and cancellation conditions for SS and elastically supported (ES) beams under a moving load. The authors justify the excitation of resonances induced by load trains with significant amplitudes or imperceptible resonances based on the free vibration study. In [17] the cancellation phenomenon is addressed considering heavily damped beams. Finally in [18] the authors investigate resonance and cancellation conditions in beams with different boundary conditions, and optimal span lengths for the supression of resonance are presented.

In the previous works, soil-structure interaction (SSI) is always disregarded and classical boundary conditions are assumed for the bridge deck. Only a few authors have investigated the dynamic response of beams or bridges taking into account the radiation of the waves transmitted through the soil. According to some authors in certain soil environments, an increase in the fundamental natural periods of moderately flexible structures due to SSI may have a detrimental effect on the structural behaviour [19]. The work presented herein arises in this context.

A concise review on the historical evolution of the soilstructure interaction field may be found in [20]. For the application of railway bridge structures, which is the object of this investigation, some authors [21-24] suggest that the resonant response of a railway bridge could be considerably affected by the soil flexibility, leading to a reduction of the resonant speeds and of the transverse amplitudes at the deck level due to the increase of damping. In [21] a qualitative analysis of the dynamic SSI of a portal frame railway bridge based on dynamic stiffness functions is presented. The authors study train-bridge resonance of the bridge model using a direct integration method. The authors conclude that the contribution to the modal damping ratios of the coupled soil-bridge system is substantial, especially for the lower range of the soil elastic modulus, and that this effect may affect the situation in which the designer cannot meet the requirements on deck vertical acceleration according to design codes. Some of the authors of the present contribution have also studied the dynamic soil-bridge interaction in high speed railway lines [23]. The analysis is conducted using a general and fully three-dimensional multi-body boundary element-finite element (BEM-FEM) model formulated in the time domain. The authors conclude that SSI affects the structure dynamic behaviour: the fundamental periods and damping ratios of the response are higher when SSI is considered. In [24] a FE model including the effect of SSI to calculate railway bridge natural frequencies is presented. The FE model includes the bridge deck and piers, foundations, soil, and water. The calculated natural frequencies taking into account the fluidstructure interaction effect are always lower than in the absence of it.

In the opinion of the authors of this contribution, there is a need to understand how SSI effects affect the free vibration re- 
sponse of beams, and the maximum free vibration and cancellation phenomena, which are the fundamental and basic aspects governing resonance. Past studies indicate that taking into account the effects of the wave propagation through the soil will affect bridge natural frequencies and maximum responses, but no studies have been found approaching the problem with the required generality, in terms of structural and soil properties, to be able to derive general trends and conclusions of the basic phenomena. A study is presented in what follows using simple models for the structures and the vehicles, with the aim of determining the main parameters that govern the resonant response of beam bridges when SSI is taken into account, and how the critical speeds and amplitudes evolve with them.

\section{Formulation and approach adopted for the analysis}

\subsection{Approach of the investigation}

The SSI problem previously described is investigated numerically in what follows. The formulation of the model used for the analysis is presented in section 2.2. The model is based on a fully coupled three-dimensional (3D) BEM-FEM formulation in the time domain. The SSI problem is analysed by domain decomposition in the soil and structure sub-domains, represented with the BEM and the FEM, respectively. BEM-FEM coupling is performed directly. A scheme showing the main parts of the model is represented in Figure 2.

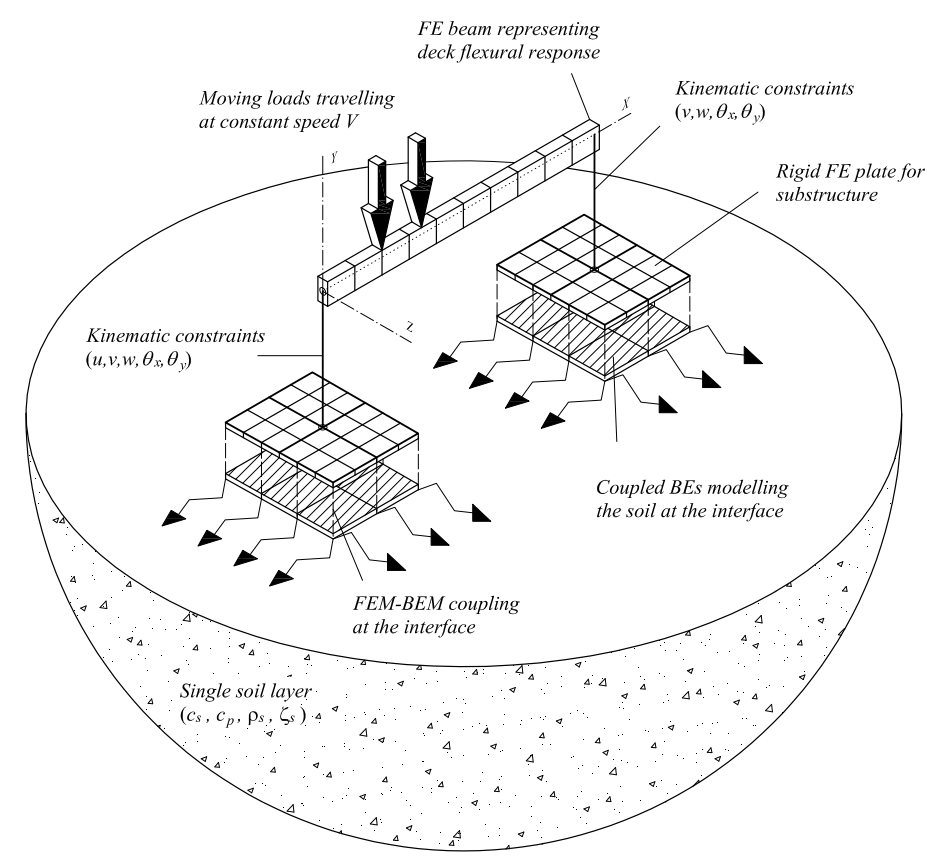

Figure 2: Schematic representation of the BEM-FEM model

The main features of the BEM-FEM model are:

- A beam FEM is used to represent the deck flexural behaviour under moving loads, therefore assuming that the maximum transverse response of the structure is mainly governed by longitudinal bending deformation. This decission is justified by the facts that: (i) according to previous studies [11, 25], short to medium span SS railway decks are expected to exhibit maximum vertical acceleration levels at mid-span; (ii) in reinforced concrete slabs or prestressed concrete girder decks, usual typologies for the range of lengths under consideration, resonances of the first torsion mode are not determinant in the assessment of the Ultimate Limit State of vertical acceleration [25]; (iii) the objetive of this investigation is to evaluate SSI effects on the main resonant problem that railway decks may experience under railway traffic.

- The beam bridges are idealised as Bernoulli-Euler beams in a finite element context. The beam is discretized using two node beam elements with tension, compression, torsion (not excited considering the 2D nature of the applied loads), and bending capabilities. The choice of the Bernoulli-Euler theory is well suited for the analysis of railway bridges in this study due to the slenderness ratios of typical railway decks $[1,26]$. Moreover, the frequency range of interest in the study is low (under $30 \mathrm{~Hz}$ ) and mismatches between Bernoulli-Euler and Timoshenko beams are expected above $50 \mathrm{~Hz}$ [27].

- The influence of the track and the ballast, which can also affect the dynamic behaviour of the bridge [28-32], has been taken into account only by means of its associated dead mass. A detailed vehicle idealisation, that would cause a reduction in the vibration levels of the bridge [33, 34] and the ground [35], is also disregarded, and a moving load model has been used during the investigation. These simplifications, in line with common design practices, have also been adopted in prior investigations of the resonance and cancellation phenomena in railway bridges $[11,13,17,18]$, and it has been considered convenient in a first approach to the problem.

- The railway excitation is introduced as a sequence of moving loads travelling at constant speed, therefore neglecting vehicle-structure interaction effects. The gradual nature of the wheel loads application process close to the abutments due to the distributive effect of rails, sleepers and ballast must be simulated in order to avoid unrealistic high frequency modal contributions. To this end, a load distribution function based on the Zimmerman-Timoshenko solution for an infinite beam on Winkler foundation, is applied to the axle load modulus in the abutments proximity. Details of the formulation may be found in [36].

- The beam end sections are connected through kinematic constraints to two rigid plates representing the lower surface of shallow foundations at the abutments. These plates are coupled to the boundary elements simulating the interaction with the soil. With this simple idealization, the essence of the wave propagation problem is isolated from the foundations geometry, and its influence is evaluated considering only the bridge vibration response [37]. 
- Regarding the soil treatment, a homogeneous soil with constant properties is admitted.

- The Green's function for an elastic half-space is used as the fundamental solution for displacements and tractions in the BEM [38]. Therefore, the boundary element discretisation is limited to the interface between the soil and the plates.

- The soil is discretized using nine node rectangular quadratic boundary elements.

- Coupling of the BEM and FEM equations is carried out by imposing equilibrium and compatibility conditions at the soil-structure interface. Both systems of equations are assembled into a single system, together with the equilibrium and compatibility conditions [39].

The described model is implemented in the SSIFiBo toolbox for MATLAB previously developed by Galvín and Romero [40-42]. The FEM module of the toolbox does not include any pre-processor. Instead, a gateway for commercial software allows importing directly the structure model. Using this model, SSI effects on the transverse response of beams traversed by moving loads at constant speeds are studied by means of four complementary steps:

1. First (section 3.1), the static response of the soil-bridge systems under study is evaluated. A relative stiffness parameter relating the beam flexural and the soil flexibilities is obtained.

2. Second (section 3.2) the variation of the fundamental natural frequencies of the bridges under study considering SSI is analysed. It should be remarked that, as explained in section 2.4 , the bridges and soil properties have been selected covering a wide range of realistic combinations in the design of SS railway bridges.

3. In third place (section 3.3) the structures response is analysed under the circulation of a single load in a wide range of speeds in order to determine the conditions for maximum response and cancellation during the free vibration phase (once the load has left the structure). General conclusions about the influence of the soil flexibility are extracted after the sensitivity analysis performed. These conclusions are consistent with the frequency evolution presented in section 3.2.

4. Finally (section 4) the dynamic response of a bridge case study is analysed under resonant conditions caused by the circulation of trains of loads. The evolution of the resonant amplitudes with the soil properties and its relation with the free vibration response previously observed are shown.

\subsection{BEM-FEM mathematical formulation}

The BEM is based on a time marching procedure to obtain the time variation of the boundary unknowns; i.e., displacements and tractions. The $k-t h$ component for displacements and tractions over the boundary is approximated from the nodal values $j$ at each time step $m, u_{k}^{m j}$ and $p_{k}^{m j}$, using the space interpolation functions $\phi^{j}(r)$ and $\psi^{j}(r)$, for tractions and displacements, respectively. After interpolating the boundary variables, the integral representation of the displacement $u$ at a point $i$ on the boundary becomes [41]:

$$
\begin{aligned}
c_{l k}^{i} u_{k}^{i}\left(\mathbf{x}^{i}, t\right) & =\sum_{m=1}^{n} \sum_{j=1}^{Q}\left\{\left[\int_{\Gamma_{j}} U_{l k}^{n m} \psi^{j} d \Gamma\right] p_{k}^{m j}\right. \\
& \left.-\left[\int_{\Gamma_{j}} P_{l k}^{n m} d \tau \phi^{j} d \Gamma\right] u_{k}^{m j}\right\}
\end{aligned}
$$

where $Q$ is the total number of boundary nodes and $\Gamma_{j}$ represents the elements to which node $j$ belongs. Time kernels $U_{l k}^{n m}$ and $P_{l k}^{n m}$ are respectively computed through the fundamental solution for displacements and tractions due to a point load acting at $\mathbf{x}^{i}$ in the $l$ direction. These kernels are analytically integrated by parts using constant and linear piecewise time interpolation functions for tractions and displacements [38], respectively. Equation (1) may be written in a more compact form as:

$$
c_{l k}^{i} u_{k}^{n i}=\sum_{m=1}^{n} \sum_{j=1}^{Q}\left[G_{l k}^{n m i j} p_{k}^{m j}-\widehat{H}_{l k}^{n m i j} u_{k}^{m j}\right]
$$

Once the integral-free term $c_{l k}^{i}$ is included in the system matrix, the integral representation for point $i$ at time $t=n \Delta t$ becomes:

$$
\mathbf{H}^{n n} \mathbf{u}^{n}=\mathbf{G}^{n n} \mathbf{p}^{n}+\sum_{m=1}^{n-1}\left[\mathbf{G}^{n m} \mathbf{p}^{m}-\mathbf{H}^{n m} \mathbf{u}^{m}\right]
$$

where $H_{l k}^{n m i j}$ collects for $c_{l k}^{i}$ when $i=j$ and $n=m$.

The FEM equation at time step $n$ is defined as [43]:

$$
\mathbf{M} \ddot{\mathbf{u}}^{n}+\mathbf{C} \dot{\mathbf{u}}^{n}+\mathbf{K} \mathbf{u}^{n}=\mathbf{f}^{n}
$$

where $\mathbf{M}, \mathbf{C}$ y $\mathbf{K}$ are the mass, damping, and stiffness matrices, respectively. $\mathbf{u}^{n}, \dot{\mathbf{u}}^{n} \mathrm{y} \ddot{\mathbf{u}}^{n}$ represent nodal displacement, velocity, and acceleration vectors, respectively, and $\mathbf{f}^{n}$ is the load vector including the effect of the constant moving load at each timestep.

Equation 4 is solved using an implicit time integration GN22 Newmark method [43, 44]. An equivalent dynamic stiffness matrix is defined:

$$
\mathbf{D} \mathbf{u}^{n}=\mathbf{f}^{n}+\mathbf{f}^{n-1}
$$

Coupling of BEM and FEM equations (Equations 3 and 5) is carried out by imposing equilibrium and compatibility conditions at the soil-structure interface. Both systems of equations are assembled into a single global system, together with the equilibrium and compatibility equations [45].

As the plate foundations have been defined as rigid bodies in a first approach through kinematic constraints, the BEM Equation (3) is expressed in terms of the kinematic constraint matrix $\mathbf{L}$ relating the displacements and tractions of the central point of the plate, $\mathbf{u}_{0}$ and $\mathbf{p}_{0}$, respectively, with any other point for each foundation: 


$$
\mathbf{H}^{n n} \mathbf{L} \mathbf{u}_{0}^{n}=\mathbf{G}^{n n} \mathbf{L} \mathbf{T} \mathbf{p}_{0}^{n}+\sum_{m=1}^{n-1}\left[\mathbf{G}^{n m} \mathbf{L} \mathbf{T} \mathbf{p}_{0}^{m}-\mathbf{H}^{n m} \mathbf{L} \mathbf{u}_{0}^{m}\right]
$$

where equilibrium of forces at the interface $\Gamma$ is fulfilled integrating nodal tractions according to the element shape function matrix $\mathbf{N}$ :

$$
\mathbf{f}=\int_{\Gamma} \mathbf{N}^{T} \mathbf{p} \mathbf{N} d \Gamma=\mathbf{T} \mathbf{p}
$$

The time step $\Delta t$ for the analysis is set sufficiently small to properly integrate the structure dynamic response and load excitation. This may be expressed as:

$$
\Delta t=\min \left(\frac{2 \pi}{\omega_{1} k_{\omega}}, \frac{L}{V k_{v}}\right)
$$

where $\omega_{1}$ corresponds to the fundamental frequency of the beam, $L$ is the beam length, and $V$ the load speed. Parameters $k_{\omega}$ and $k_{v}$ define time discretizations for the structure fundamental period and the load passage time, respectively.

The chosen time step determines the spatial boundary element discretization according with the stability parameter $\beta=$ $c_{s} \Delta t / \Delta l$, where $\Delta l$ is the distance between two nodes of a boundary element, and $c_{s}$ is the shear wave propagation speed in the soil. In this work, a stability parameter $\beta=0.5$ has been considered.

The finite element representation is determined by the bridge bending wavelength discretization. Minimum wavelength is defined by the maximum frequency range and the phase bending wave propagation speed $c_{B}=\sqrt[4]{\omega_{1}^{2} E I_{z} / m_{b}}$, where $E I_{z}$ is the beam cross-section bending stiffness and $m_{b}$ is the beam mass per unit length. This work considers 20 elements for the minimum wavelength.

\subsection{Analytical solution for the ES beam}

An exhaustive sensitivity analysis is carried out and presented in section 3 in order to detect general tendencies on the effects of SSI on the beams dynamic response. This analysis covers the ranges of main properties to be expected in existing SS railway bridges of moderate lengths and different types of soils. The selection of the main variables for the parametric analysis is inspired on the dynamic response of a BernoulliEuler ES beam (see Figure 3(a)), studied by one of the authors in the past [11]. By neglecting shear deformation and rotary inertia effects of the sections in the Bernoulli-Euler theory, the response of high-frequency modes or in the case of very high speeds could be affected [27]. Nevertheless, as pointed out before in section 2.1, the frequency range of interest in the study is low (under $30 \mathrm{~Hz}$ ) and mismatches between Bernoulli-Euler and Timoshenko beams are expected above $50 \mathrm{~Hz}$ [27].

Let us assume that (i) the beam is supported on two massless identical elastic springs with vertical stiffness $K_{v}$; (ii) structural damping, shear deformation and rotary inertia are neglected. The natural frequencies of the ES beam [46] may be obtained solving the frequency equation
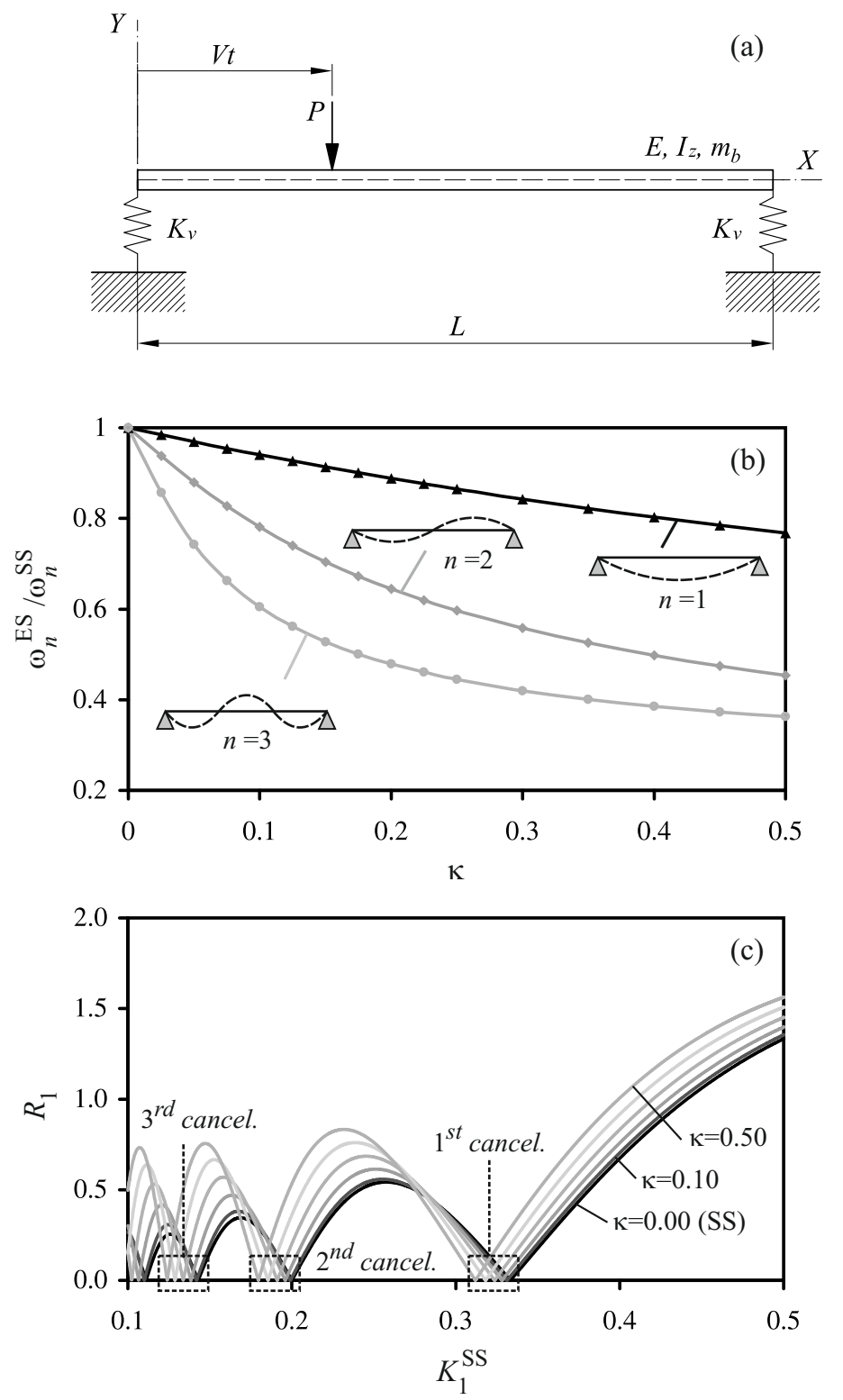

Figure 3: ES Bernoulli-Euler beam. Evolution of natural frequencies and free vibration amplitudes with $\kappa \in[0.00-0.50]$

$$
\begin{gathered}
\left(\frac{\pi^{3}}{\kappa}\right)+\frac{\pi^{3}}{\kappa} \lambda^{3} \frac{\sinh (\lambda) \cos (\lambda)-\cosh (\lambda) \sin (\lambda)}{\sin (\lambda) \sinh (\lambda)} \\
+\lambda^{6} \frac{1-\cos (\lambda) \cosh (\lambda)}{2 \sin (\lambda) \sinh (\lambda)}=0
\end{gathered}
$$

In Equation (9) $\kappa=E I_{z} \pi^{3} /\left(K_{v} L^{3}\right)$ is the ratio of the flexural rigidity of the beam to the stiffness of the elastic supports. Let $\lambda_{n}=\lambda_{n}(\kappa)$ stand for the $n-t h$ root of the frequency equation. $\lambda_{n}$ and the ES beam $n-t h$ circular frequency are related as per

$$
\omega_{n}^{\mathrm{ES}}=\left(\frac{\lambda_{n}(\kappa)}{L}\right)^{2} \sqrt{\frac{E I_{z}}{m_{b}}} \Rightarrow \frac{\omega_{n}^{\mathrm{ES}}}{\omega_{n}^{\mathrm{SS}}}=\left(\frac{\lambda_{n}(\kappa)}{n \pi}\right)^{2}
$$

where $\omega_{n}^{\text {SS }}$ is the circular frequency of the same beam with simply-supported boundary conditions. Notice that $\kappa=0$ corresponds to the SS case and that $\lambda_{n}(\kappa=0)=n \pi$. Figure 3(b) 
shows the reduction experienced by the first three natural frequencies of the ES beam with the relative stiffness parameter $\kappa \in[0.00-0.50]$.

As stated in [11] the free vibration response of a beam left by the passage of a single load provides essential information in relation with its vibrational response under resonant conditions. The formulation for this type of solution, considering only the contribution of the ES beam fundamental mode and in the absence of damping, is detailed in [11] and represented in Figure 3(c). The maximum amplitude of the displacement response in free vibration, $\xi_{1}$, non-dimensionalised by the static solution, $\xi_{1, s t}$, from now on $R_{1}$, is a function of the non-dimensional speed parameter $K_{1}^{\mathrm{SS}}$ and of the relative flexibility of the supports, $\kappa$ :

$$
R_{1}=\frac{\xi_{1}}{\xi_{1, s t}} \quad K_{1}^{\mathrm{SS}}=\frac{\Omega_{1}^{\mathrm{SS}}}{\omega_{1}^{\mathrm{SS}}}=\frac{\pi V}{\omega_{1}^{\mathrm{SS}} L}=\left(\frac{\lambda_{1}}{\pi}\right) K_{1}^{\mathrm{ES}}
$$

In Equation (11) $\omega_{1}^{\mathrm{SS}}$ is the circular frequency of the BernoulliEuler SS beam in its fundamental mode, while $\Omega_{1}^{\mathrm{SS}}=\pi V / L$ is used to represent the forcing frequency of the system fundamental mode. Notice that the non-dimensional speed may be defined both in the SS or ES configurations and that these are related by the ratio $\left(\lambda_{1} / \pi\right)$. In Figure 3(c) the former is used as it is independent of $\kappa$. Based on this, the length and fundamental frequency of the beam have been considered fundamental quantities for the parametric study presented in section 3, along with the soil flexibility, expressed in terms of the dilatational and shear wave speeds, $c_{p}$ and $c_{s}$. In Figure 3(c) it may be noticed that maximum free vibration and cancellation conditions successively take place as $K_{1}^{\mathrm{SS}}$ increases. The main interest of this response is that in the ES beam case resonances caused by trains of equidistant loads that take place at a critical speed that coincides with a maximum free vibration condition are expected to show considerably high amplitudes, while when the resonant speed takes place close to a cancellation condition, it practically vanishes. Finally, as the supports become more flexible (and $\kappa$ increases) the non-dimensional speed for cancellation decreases. This is related with the reduction experienced by the beam frequencies with the flexibility of the supports.

The main objectives of this study include: (i) to analyse if these trends also take place when SSI is considered; and (ii) to get an insight of the variables that deviate the response with respect to the ES beam analytical solution. In section 3 the evolution of the natural frequency and free vibration response of several beam-type bridges with the soil properties is evaluated numerically, using the BEM-FEM model which formulation is described in section 2.2. The analytical response of the ES beam is used as a source of comparison, and as a guide in order to select the parameters for the sensitivity study.

\subsection{Definition of the sensitivity analysis}

Beams of lengths ranging from 12.5 to $25 \mathrm{~m}$ in increments of length of $2.5 \mathrm{~m}$ are considered, covering the typical span lengths susceptible to experience high deck vertical accelerations under resonant conditions. The range of fundamental frequencies realistic for each span is selected from the band prescribed by
Eurocode 1 [47] for the application of simplified methods (see Figure 4), therefore the vast majority of existing and potential SS bridges fundamental frequencies are expected to fall within these limits. Three evenly-spaced sample values between $0 \%$ and $70 \%$ of Eurocode 1 upper frequency limit have been analysed. These frequencies are referred to as $f_{1,000}, f_{1,035}$ and $f_{1,070}$ in what follows. As can be extracted from the studies presented in [33], the majority of railway bridges for conventional and High-Speed lines fall within the selected range.

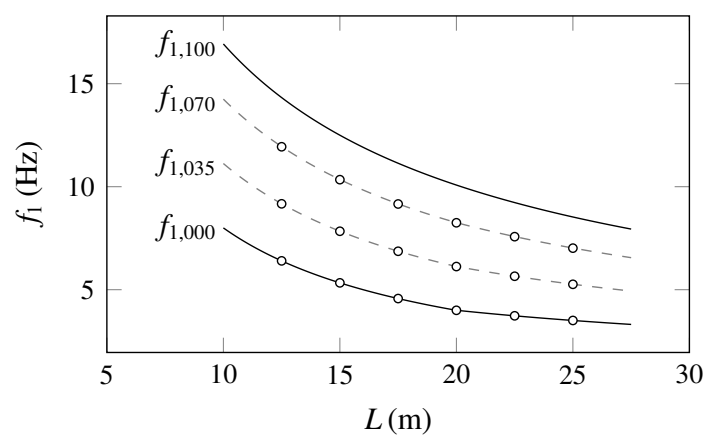

Figure 4: Eurocode 1 [47] lower and upper frequency limits for simplified dynamic analysis. Circles: reference SS bridges under study

One value of linear mass for each length is adopted in a first approach, in particular $m_{b}=L(m) \cdot 1000 \mathrm{~kg} / \mathrm{m}^{2}$. The mass of the structure will affect the level of vertical acceleration at resonance, but it has not been selected as a parameter for the sensitivity study as it does not govern the maximum free vibration and cancellation conditions in the ES case. Structural damping is not assigned to the beams in section 3. No material damping is assigned to the soil either. Eliminating damping permits a better understanding of the soil flexibility effects, and a direct comparison of the maximum free vibration and cancellation conditions with those of the ES case. Identical $5 \mathrm{~m} \times 5 \mathrm{~m}$ foundation plates are considered in all the cases to represent the soil-substructure interaction surface.

As for the soil properties, three homogeneous soil types are defined with flexibilities covering the AASHTO classification [48]. In particular $s$ and $p$-wave speeds of $c_{s}=$ $\{150,220,365\} \mathrm{m} / \mathrm{s}$ and $c_{p}=2 c_{s}$ are considered, entailing a Poisson's ratio $v=1 / 3$ for the soil. Soil density has been set equal to $1800 \mathrm{~kg} / \mathrm{m}^{3}$ in all the cases. Therefore 72 BEM-FEM models are evaluated in the following sections (18 bridges $\mathrm{x} 4$ soil types including an infinitely rigid soil).

The sensitivity analysis proposed by the authors presents limitations such as: (i) the size of the foundation plates is considered constant; (ii) the actual geometry of the foundations is not simulated; (iii) the mass of the beams is not evaluated as a parameter; (iv) damping, apart from the radiation damping in the soil, is not included in the analysis. These limitations are a consequence of the considerable computational cost entailed by BEM-FEM coupled models integrated in the time domain. Additionally, no other studies have been presented in the past evaluating SSI effects on the resonant response of beams under moving loads considering a wide range of structural and 
soil properties. In the authors opinion the basic parameters that govern the beam moving load problem including the flexibility of the soil have been taken into account in this work, and provide an interesting insight regarding the main trends of the phenomenon. The conclusions to this investigation could serve as a base for future more detailed studies related with the vibrational response of bridges under resonant conditions including SSI effects.

\section{Sensitivity analysis results}

\subsection{Static response of the bridges under study}

First, the static response of the structures is obtained under a vertical load $P_{v}$ applied at the beams mid-span section. The vertical displacement of the centre of the foundation plates, $\delta_{y}^{f}$, is obtained for each beam solving a quasi-static analysis of the BEM-FEM model. Let an equivalent stiffness value of $K_{v}$ be defined as $K_{v}=P_{v} /\left(2 \delta_{y}^{f}\right)$. Finally, in order to present the results similarly to those of the ES case, the relative stiffness parameter $\kappa$ is computed as per its definition in the previous section i. e., $\kappa=E I_{z} \pi^{3} /\left(K_{v} L^{3}\right)$. Figure 5 shows the value of $\kappa$ for the bridge-soil combinations under study. Notice that $\kappa=0$ corresponds to the SS case. The lines in the plot are grouped for the three soil shear wave speeds, and each line colour represents a beam length. In the horizontal axis the beams natural frequencies including SSI are not represented explicitly. Instead, the fundamental frequency of the associated SS beam (infinitely rigid soil conditions) is referred to, expressed as a proportion of the Eurocode 1 frequency band for each length (see Figure 4).

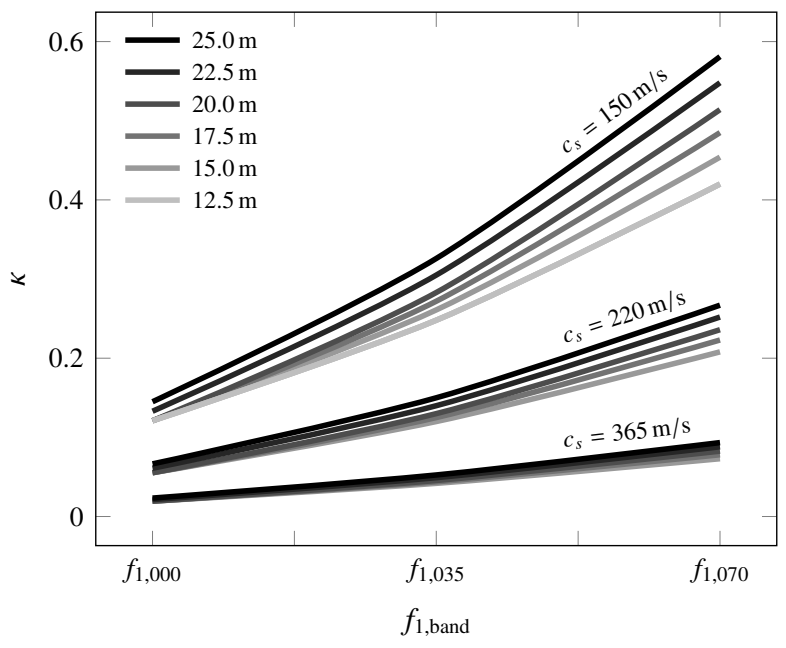

Figure 5: Non-dimensional stiffness parameter $\kappa$ of the soil-foundation system for the beam-soil cases under study

Higher values of $c_{s}$ (stiffer soils) correspond to lower values of $\kappa$, as $K_{v}$ increases independently of the beam properties. As a single value of linear mass has been considered for each beam frequency, beams with higher natural frequencies, in the absence of soil, present a higher bending stiffness and, therefore, lead to higher $\kappa$ values. In relation with the definition of the beams catalogue, longer bridges present lower natural frequencies (for a particular band of the Eurocode $1 f_{1}-L$ definition). Due to the linear mass variation considered in terms of the length, longer bridges present higher values of the quotient $E I_{z} / L^{3}$ and, therefore, of $\kappa$. This effect is clearer with more flexible soils, as the reduction in the fundamental frequency of the bridges when SSI is included is more evident, as it will be shown in the following section.

\subsection{Modal identification of the bridges under study}

In what follows the results of a modal analysis performed on the bridges under study is presented. The fundamental natural frequency is identified from the impulse response of the 18 beams, considering the three soil types $\left(c_{s}=\right.$ $\{150,220,365\} \mathrm{m} / \mathrm{s})$ and infinitely rigid soil conditions.

In order to show the frequency variation with $\kappa$ for all the bridges under study, Figure 6 is included. Circles indicate the fundamental frequency reduction including SSI with respect to infinitely rigid soil conditions. Figures 6(a)-(c) represent the results for the three soil types under consideration, while Figure 6(d) combines all the beam-soil cases analysed. In all the plots, the thick black trace corresponds to the analytical solution for the fundamental mode of the ES Bernoulli-Euler beam shown in Figure 3(b). Finally, in each graph different frequency bands are distinguished in shaded areas, and circle sizes are proportional to the beams lengths.

The flexibility of the soil leads to a decrement in the fundamental frequency of the bridges under study. This decrement is more evident in the case of bridges with higher natural frequencies (and therefore, higher values of $\kappa$ ). Structures with frequencies along the $f_{1,000}$ band in the SS case experience a reduction in the interval $4.4-5.9 \%$. Those corresponding to the frequency band $f_{1,035}$ show a reduction with SSI in the range $7.8-15.7 \%$. Finally, the beams with the highest natural frequencies show the highest reductions when compared to infinitely rigid soil conditions, i.e., $15.7-25.5 \%$. For each frequency group, bridges with longer spans are most affected by soil conditions. This is due to the fact that longer bridges present higher $\kappa$ values, as shown in Figure 5. Notice that according to the the ES beam analytical solution, the natural frequency reduction increases with the relative stiffness of the supports (see Figure 3(b)).

From the analysis of the results presented it may be concluded that: (i) the frequency variation experienced by the structures when SSI is included follows the general trend shown by the ES Bernoulli-Euler beam in terms of the relative stiffness parameter $\kappa$; (ii) soil-beam systems with similar $\kappa$ values show similar frequency variations, independently of the soil properties and the beam initial natural frequency; (iii) for each soil type and frequency band, shorter bridges show a slightly higher deviation with respect to the analytical solution of the ES beam.

\subsection{Maximum free vibration and cancellation phenomena un- der a single moving load}

In this section the free vibration response after the passage of a single load in the beam-soil systems is investigated. The results are presented as in section 2.3 , following the works of 


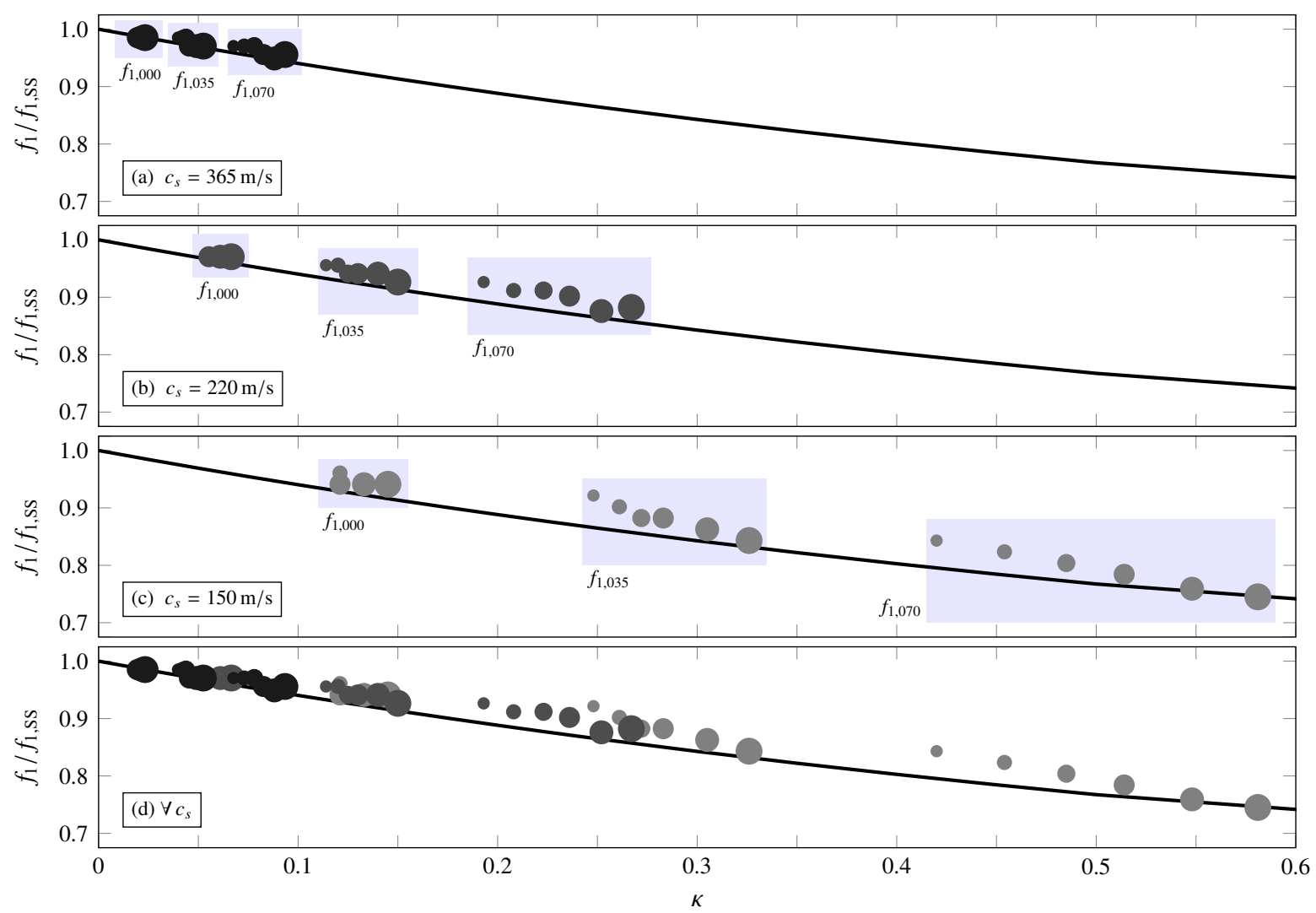

Figure 6: Fundamental frequency variation vs. $\kappa$

- ES beam $\mathbb{e c C} L_{i} \square c_{s}=365 \mathrm{~m} / \mathrm{s} \square c_{s}=220 \mathrm{~m} / \mathrm{s} \square c_{s}=150 \mathrm{~m} / \mathrm{s}$

[11] for the ES case. Therefore, the maximum amplitude of the displacement response at mid-span in free vibration nondimensionalised by the static solution, $R$, is obtained as a function of the speed parameter $K_{1}^{S S}$ (see Equation 11).

For each one of the beams under analysis, and considering the three soil types and the SS case, 70 evenly spaced values of $K_{1}^{S S}$ have been selected between 0.1 and 0.5 . As detailed in [11] this range suffices to cover the circulation speeds expected in actual railway systems. In order to capture accurately the variation of the cancellation conditions when SSI is included, twenty additional values are computed within the ranges $[0.85,1.15] K_{1, c i}^{S S}$, where $K_{1, c i}^{S S}$ represents the ith nondimensional cancellation speed of the first mode in the SS case.

A representative case study of a bridge with intermediate values of span length and fundamental frequency $(L=17.5 \mathrm{~m}$, $f_{1,035}$ ) is selected from the analysed catalogue to show the main tendencies obtained in the study (see Figure 7). The same type of response in free vibration is obtained in the 18 bridges analysed.

When considering SSI, cancellation and maximum free vibration situations alternate following a similar pattern to that of the ES case in its fundamental mode. When the load crosses the beam at a certain speed close to a cancellation condition, the levels of free vibration left on the structure become minimum. Between each cancellation condition, speeds leading to maximum free vibration levels take place. In sections 3.3.1 and 3.3.2 some worth emphasizing factors related to the soil influence on the cancellation and maximum free vibration conditions are discussed.

\subsubsection{Influence of SSI in the cancellation phenomena}

An accurate prediction of the cancellation speeds is crucial, for instance, when planning an experimental test with the aim of measuring structural parameters i.e., damping. In this section, the influence of SSI in the variation of the cancellation speeds compared to those of the SS case is investigated.

In Figure 7 the first and second cancellation zones have been zoomed in. It may be observed that, following the trends of the ES case, the cancellation speed decreases as the relative stiffness parameter $\kappa$ increases. This variation is associated with the descent of the structure fundamental frequency with the soil flexibility, suggested in $[21,23,24]$ and shown in this investigation (see Section 3.2). A similar pattern is found in the speeds associated to maximum free vibration speeds.

To present the results obtained in all the beams under study, the reduction of the cancellation speeds of the coupled soilbeam systems $\left(V_{1, c i}\right)$ with respect to the corresponding SS case cancellation speeds $\left(\bar{V}_{1, c i}\right)$ are obtained in terms of $\kappa$. The results are represented in Figure 8 using the same nomenclature as in Figure 6. Only the first and second cancellation speeds of the fundamental mode are represented for the sake of brevity. The cancellation speeds obtained analytically for the ES Bernoulli- 


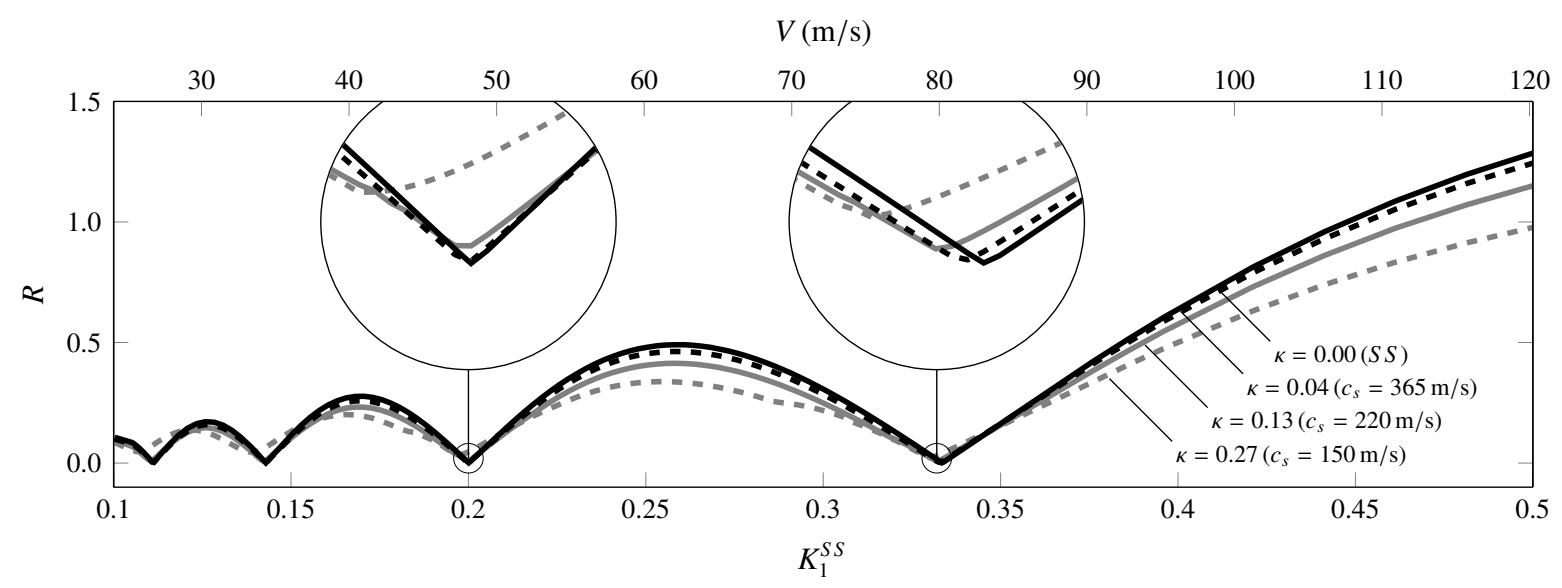

Figure 7: Non-dimensional free vibration amplitude as a function of the speed. Representative case study: $L=17.5 \mathrm{~m}, f_{1,035}$ $\longrightarrow \mathrm{SS},--c_{s}=365 \mathrm{~m} / \mathrm{s},-c_{s}=220 \mathrm{~m} / \mathrm{s},--c_{s}=150 \mathrm{~m} / \mathrm{s}$

Euler beam (fundamental mode) are plotted in black trace in the same plots.

The relative stiffness parameter $\kappa$ proves to be again the key factor, also in the prediction of the cancellation speeds. Beam-soil models obtained from different combinations of span length, bridge frequency and soil type, present similar values of the $\bar{V}_{1, c i} / V_{1, c i}$ ratio for similar values of $\kappa$. The deviation with respect to the analytical solution of the ES case is again slightly higher for shorter bridges.

The cancellation speeds experience a slightly noticeable variation with the soil flexibility in the case of beams with the longest spans, highest fundamental frequencies, and for the most flexible soil of the AASHTO classification. The reduction experienced by the $2^{\text {nd }}$ cancellation speed shows an upper bound of $\sim 10 \%$, a slightly higher value than that of the $1^{\text {st }}$ cancellation speed $(\sim 7 \%)$ in the aforementioned cases, where the influence of SSI maximizes. Further studies incorporating the simplifications undertaken in this investigation, such as the actual geometry of the foundations and material damping of the structure and the soil, will allow to quantify these qualitative trends for particular situations.

\subsubsection{Influence of SSI in the maximum free vibration}

One of the major interests of the investigation undertaken is to determine how the predicted maximum bridge response can be affected by SSI. As it may be observed in the bridge case selected (see Figure 7), out of the vicinity of each cancellation speed, the use of a coupled soil-bridge system leads to a reduction of the bridge maximum free vibration amplitude. This behaviour differs from the one observed in the ES case (see Figure 3(c)), where the maximum level of free vibrations of the ES beam may be associated to high or low values of the supports flexibility depending on the non-dimensional speed, and a SS model of the beam does not always lead to the most conservative response in terms of structural vibration levels. It is convenient to recall here that no damping is considered in the ES case either, therefore the change in the trend when considering SSI seems to arise from the inherent damping associated to the soil wave radiation.

The effect of the radiation damping in the soil is also perceivable in the cancellation situations, where the free vibration amplitude does not vanish completely. Nevertheless, the practical implication concerns how SSI can affect the bridge peak response and, as it can be extracted from the sensitivity analysis, the free vibration levels of the beams decrease when SSI is taken into account.

In order to provide an outline of the obtained results, the attention is focused in the maximum displacement reached between the first and the second cancellation (i.e., for nondimensional speed values close to $K_{1}^{S S}=0.2576$, corresponding to the first attainable maximum for the ES beam). The variable of interest is the ratio between the maximum response obtained with the coupled beam-soil model and that of the SS model, $\bar{R}_{1, \text { max }} / R_{1, \max }$. The results are represented in Figure 9 using the convention employed in Figures 6 and 8.

The reduction obtained for different beam-soil systems is similar for similar values of $\kappa$. This reduction tends to increase as the soil becomes more flexible. This effect is attributed to the radiation damping of the soil, only present in the BEM-FEM models.

\section{Case studies}

In the previous sections it has been shown that: (i) the fundamental frequency of the beam reduces when SSI is considered, being this reduction a function of the relative stiffness parameter $\kappa$; (ii) regarding the free vibration response of a beam travelled by a single moving load, the phenomena of maximum vibration and cancellation is also present when considering SSI; (iii) the amplification of the transverse response of the beam is reduced due to the soil influence except in the proximities of the cancellation speeds.

As the bridge maximum response when travelled by a train of loads depends both on the periodicity of the loads and on the amplitude of the free vibrations left by every single load, the 

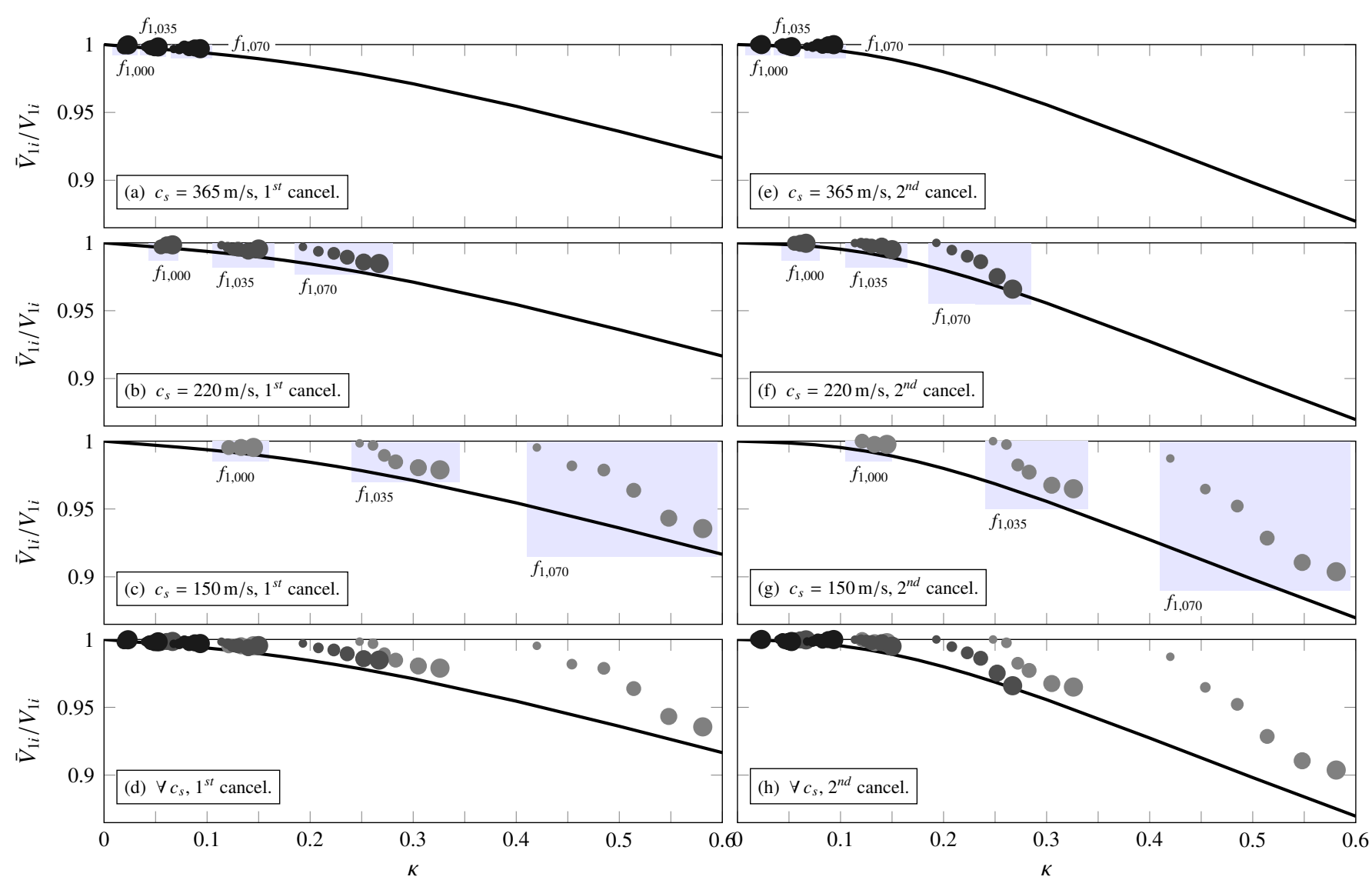

Figure 8: Variation of the cancellation speeds with $\kappa$

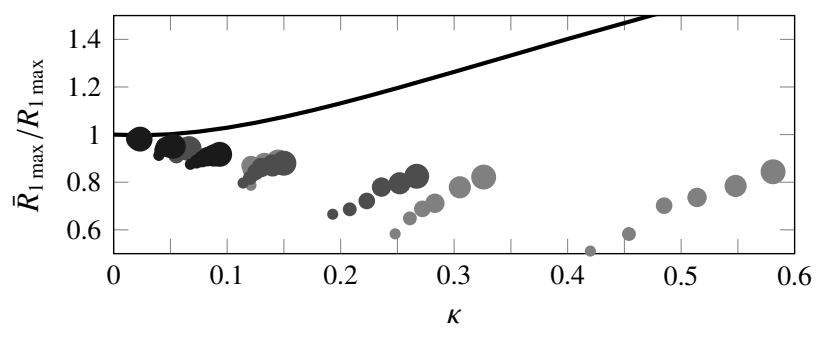

Figure 9: Variation of the maximum amplitude of free vibration with $\kappa$ - ES beam $\mathbb{C C C C} L_{i} \square c_{s}=365 \mathrm{~m} / \mathrm{s} \square c_{s}=220 \mathrm{~m} / \mathrm{s} \square c_{s}=150 \mathrm{~m} / \mathrm{s}$

aforementioned reduction brings into question whether incorporating the soil model in the prediction of the bridge resonant response may be appropriate for design or retrofit purposes.

In this context, and in order to reproduce some of the main tendencies observed during the sensitivity analysis, the bridge selected in previous sections $\left(L=17.5 \mathrm{~m}, f_{1,035}\right)$ is analysed under the circulation of HSLM trains from Eurocode 1 [47]. The structural damping assigned follows the design recommendations of Eurocode 1 for prestressed concrete bridges: Rayleigh damping of $1.18 \%$ is considered according to the bridge span
$(L=17.50 \mathrm{~m})$. As for the soil, a common value of $5.00 \%$ has been employed. Similar values have been used in [49-52]. It is important to recall here that no material damping has been considered in the sensitivity analysis presented in precedent sections. In the case studies of this section, material damping is incorporated with the aim of propose a working example of SSI from the designer point of view. The general conclusions of the investigation are therefore not affected by the values selected herein.

The following scenarios are reproduced: (i) the second resonance of the bridge fundamental mode takes place at a speed of maximum free vibration amplitude $\left(K_{1}^{S S} \approx 0.26\right.$ in Figure 7$)$; (ii) the second resonance of the bridge fundamental mode takes place at a speed close to the first cancellation one $\left(K_{1}^{S S} \approx 0.33\right.$ in Figure 7).

In Table 1, the defining parameters for the selected trains, HSLM-A1 and HSLM-A6, are included, where $N$ stand for the number of passenger coaches, $d$ for the characteristic distance of the train (or distance causing resonance) and $P$ for the axle load.

In each case study the bridge maximum response is computed along 19 equally spaced sections, $x / L=$ $\{0.05,0.10,0.15,0.20, \ldots, 0.95\}$, considering the three soil types and the SS case. The maximum response is evaluated at speeds 


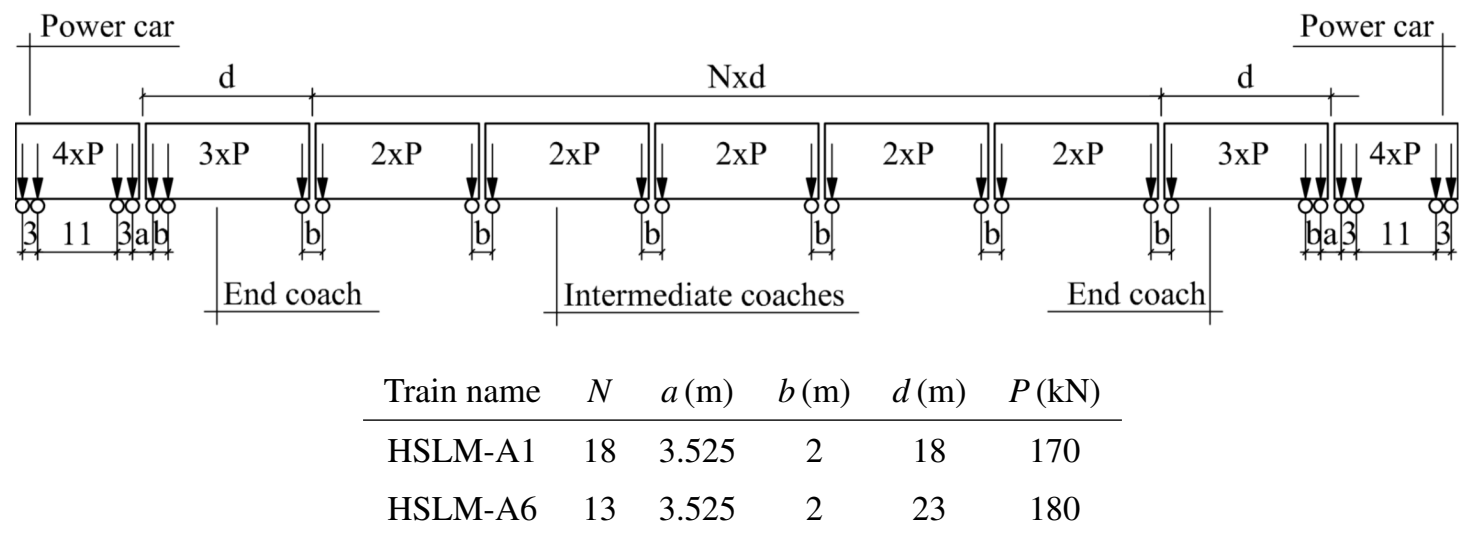

Table 1: Train load models definition

comprised between $V / d=2.0 \mathrm{~s}^{-1}$ and $V / d=4.5 \mathrm{~s}^{-1}$. Considering the characteristic distance of each train, this leads to speed ranges of $[130,292] \mathrm{km} / \mathrm{h}$ and $[166,373] \mathrm{km} / \mathrm{h}$ for the HSLMA1 and HSLM-A6 trains, respectively.

Based on the characteristic distance of both trains and the fundamental frequency of the selected bridge $(6.87 \mathrm{~Hz}$ for the case SS), the speeds that excite a second resonance of the fundamental mode are $222.58 \mathrm{~km} / \mathrm{h}$ and $284.42 \mathrm{~km} / \mathrm{h}$, for the A1 and the A6 trains respectively. As previously mentioned, these speeds correspond to values of $K_{1}^{S S}$ of 0.26 and 0.33 , respectively. Therefore the HSLM-A1 train will be forcing a maximum second resonance and the HSLM-A6 train a cancelled second resonance.

The results are represented in Figure 10 (a) and (b). A vertical dashed line indicates the $V / d$ value corresponding to the second resonance in the absence of soil $\left(V_{2}^{r} / d=f_{1}^{S S} / 2=\right.$ $3.435 \mathrm{~s}^{-1}$ ), and the corresponding acceleration time histories at mid span are represented in Figures 10 (c) and 10 (d) for these speeds.

The prediction of the infinitely rigid soil for the HSLM-A1, $5.72 \mathrm{~m} / \mathrm{s}^{2}$, clearly exceeds the serviceability limit state of vertical acceleration for ballasted tracks (dashed line at $0.35 \mathrm{~g}=$ $3.43 \mathrm{~m} / \mathrm{s}^{2}$ ). When SSI considered, the resonant speeds reduce due to the alteration of the system fundamental frequency. Also, the resonant amplitudes monotonically reduce with the soil flexibility, and for the soil with $c_{s}=220 \mathrm{~m} / \mathrm{s}$ the maximum response falls already under the prescribed limit. These results suggest that SSI may have an important influence in the assessment of the Serviceability Limit State of vertical acceleration in the design of new structures or in the evaluation of existing ones for more demanding operating conditions.

Additionally, Figure 7 shows that the cancellation of the second resonance indeed takes place also when SSI effects are included, in the same way that it happens for rigid boundary conditions.

\section{Conclusions}

In the present contribution, the dynamic response of beams travelled by moving loads is analyzed taking into account soil- structure interaction effects using a 3D BEM-FEM coupled numerical model integrated in the time domain. The main practical application of the study is the analysis of the transverse vibrations of simply-supported railway bridges considering short to medium span lengths.

In a first approach, the fundamental frequencies of all the bridges under study are identified from the response under impulse loading. Secondly, the maximum response of the beams is obtained in the free vibration phase right after a single travelling load has crossed the structure. A wide range of circulating speeds is defined and envelopes of maximum response are obtained and analysed.

From the preliminary results it is concluded that the fundamental frequency of the structures tends to that of the simplysupported case as the soil stiffness increases. The structures that are most affected by the soil flexibility are those with highest natural frequency for all the lengths. This is a consequence of the frequency evolution with parameter $\kappa$ defined as the ratio between the beam flexural stiffness an the soil rigidity. These results are consistent with the frequency evolution included in [11] for the elastically supported beam. Regarding the analysis of maximum free vibrations under the circulation of single loads, it is concluded that:

- When the SSI is taken into account speeds leading to maximum free vibration response and to cancellation sequentially take place, in the same way that occurs for the ES beam analytical case.

- As $c_{s}$ and $c_{p}$ decrease, going from stiffer to softer soils, the cancellation non-dimensional speeds decrease as in the ES case. This is related with the alteration in the beams natural frequencies due to the soil effect.

- The results obtained suggest that incorporating the soil model could have a relatively low influence in the prediction of the cancellation speeds for bridge engineering applications.

- Far from the cancellation conditions the consideration of the soil effects leads to a reduction of the bridge maximum 

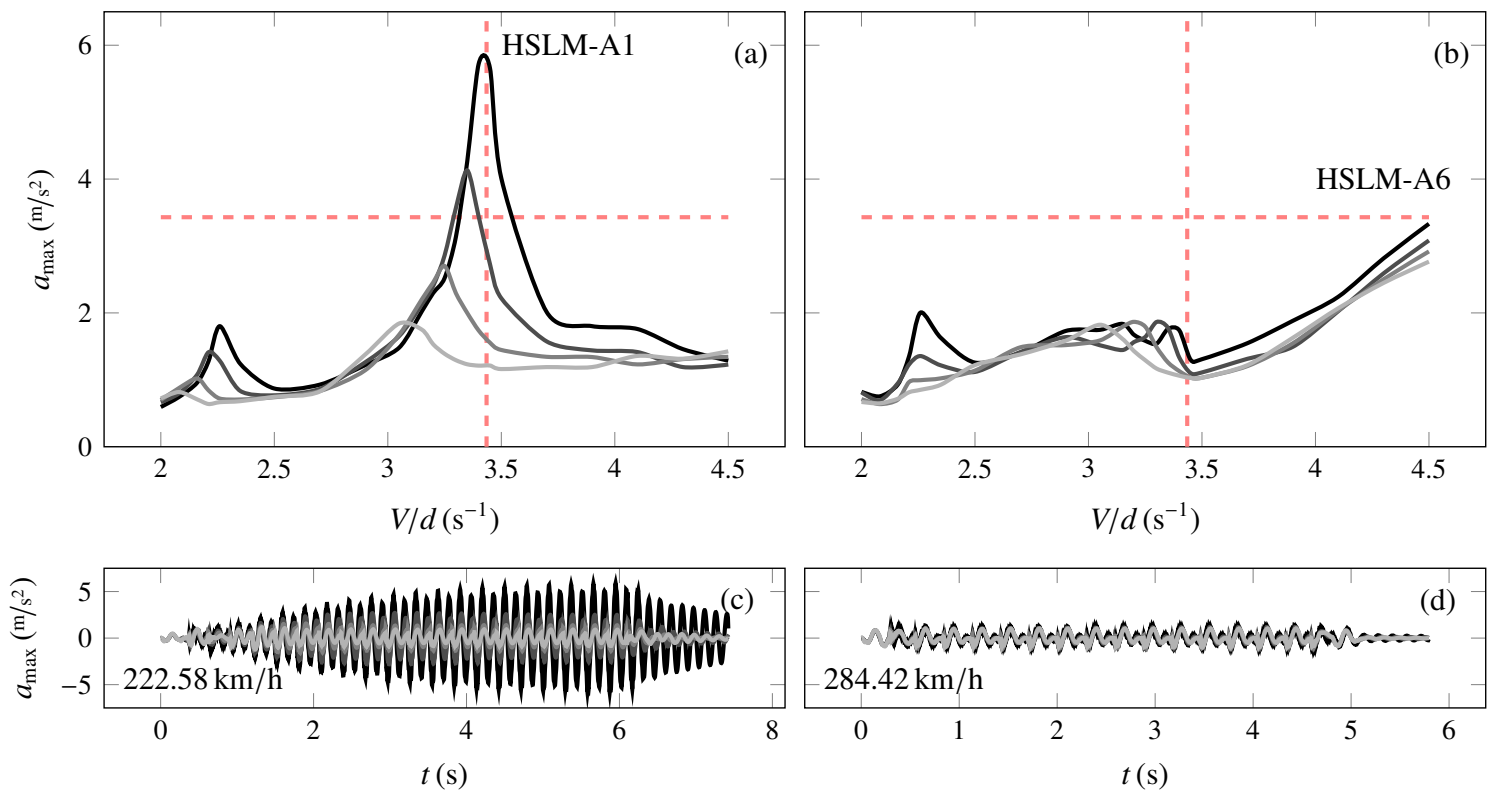

Figure 10: Maximum value of the vertical acceleration as a function of the speed parameter $V / d$. A1 and A6 trains. Representative bridge: $L=17.5 \mathrm{~m}, f_{1,035}$.

$$
\mathrm{SS},-c_{s}=365 \mathrm{~m} / \mathrm{s}, \longrightarrow c_{s}=220 \mathrm{~m} / \mathrm{s}, \stackrel{-035}{-} c_{s}=150 \mathrm{~m} / \mathrm{s}
$$

free vibration amplitudes, independently of the circulation speed. This behaviour differs from that observed in the ES case and it is a consequence of the inherent damping of the soil due to wave radiation.

Finally the response of a bridge case study has been evaluated under trains of moving loads exciting resonances of the structure fundamental frequency. It is shown that resonant speeds reduce with the soil influence. Also, when resonant speeds take place close to cancellation conditions, the structural response drastically reduces and the resonant peak becomes almost imperceptible. In the same way, the amplitude of the structure at resonance varies with the soil properties following the trends observed in the free vibration analysis.

The main conclusion of this investigation is that incorporating soil-structure interaction effects in the analysis of new simply-supported bridges or in the analysis of existing ones for retrofitting purposes could be of great importance due to the influence of soil-structure interaction in the assessment of the Serviceability Limit Sate of vertical acceleration. In-depth studies should be addressed in forthcoming contributions aimed at stablishing the practical importance of incorporating the soil model in the prediction of the bridge peak response considering realistic sub-structure geometries and experimentally measured properties of the soil.

\section{Acknowledgements}

The first two authors would like to acknowledge the financial support provided by Universitat Jaume I under the research project P1·1B2015-54. The third and fourth authors would like to acknowledge the financial support provided by the Spanish Ministry of Economy and Competitiveness (Ministerio de Economía y Competitividad) under the research project [BIA2013-43085-P]. The authors also wish to acknowledge the support provided by the Andalusian Scientific Computing Centre (CICA).

\section{References}

[1] ERRI D214, Rail bridges for speeds $>200 \mathrm{~km} / \mathrm{h}$. Final report. Part a. Synthesis of the results of D 214 research, European Rail Research Institute, 1999.

[2] T. Ishibashi, Shinkansen structures in Japan, in: FEUP (Ed.), Workshop: Bridges for high-speed railways., 2004.

[3] R. Álvarez, J. Díaz, C. Moreno, J. Santos, F. Santos, Conclusiones sobre los ensayos realizados en el "viaducto sobre el río Tajo" en la línea de alta velocidad Madrid-Sevilla. consideraciones para el proyecto de obras de paso en FFCC de alta velocidad, Hormigón y acero 214 (1999) 131140 .

[4] R. Le, B. Ripke, M. Zacher, Influence of bridge dynamics on ballast deterioration on high-speed lines, in: World Congress on Railway Research. Book of paper summaries, 1999, p. 159.

[5] L. Frýba, Vibration of solids and structures under moving loads, Thomas Telford, London, 1999.

[6] M. Olsson, On the fundamental moving load problem, Journal of Sound and Vibration 145 (2) (1991) 299 - 307.

[7] J. Gbadeyan, T. Oni, Dynamic behaviour of beams and rectangular plates under moving loads, Journal of Sound and Vibration 182 (5) (1995) 677695.

[8] S. Law, T. Chan, Q. Zeng, Moving force identification-a frequency and time domains analysis, Journal of Dynamic Systems, Measurement, and Control 121 (1999) 394-401. doi:doi: 10.1115/1.2802487.

[9] E. Savin, Dynamic amplification factor and response spectrum for the evaluation of vibrations of beams under successive moving loads, Journal of Sound and Vibration 248 (2) (2001) 267 - 288.

[10] A. Pesterev, B. Yang, L. Bergman, C. Tan, Revisiting the moving force problem, Journal of Sound and Vibration 261 (1) (2003) 75 - 91.

[11] P. Museros, E. Moliner, M. Martínez-Rodrigo, Free vibrations of simplysupported beam bridges under moving loads: Maximum resonance, can- 
cellation and resonant vertical acceleration, Journal of Sound and Vibration 332 (2) (2013) $326-345$.

[12] M. Klasztorny, J. Langer, Dynamic response of single-span beam bridges to a series of moving loads, Earthquake Engineering and Structural Dynamics 19 (1990) 1107-1124.

[13] Y. Yang, J. Yau, L. Hsu, Vibration of simple beams due to trains moving at high speeds, Engineering Structures 19(11) (1997) 936-944.

[14] L. Frýba, A rough assessment of railway bridges for high speed trains, Engineering Structures 23 (2001) 548-556.

[15] P. Museros, E. Alarcón, Influence of the second bending mode on the response of high-speed bridges at resonance, Journal of Structural Engineering 131 (3) (2005) 405-415.

[16] J. Yau, Y. Yang, Vertical accelerations of simple beams due to successive loads traveling at resonant speeds, Journal of Sound and Vibration 289 (2006) $210-228$

[17] C. Sudheesh-Kumar, C. Sujatha, K. Shankar, Vibration of simply supported beams under a single moving load: A detailed study of cancellation phenomenon, International Journal of Mechanical Sciences 99 (2015) 40 47.

[18] J.-R. Cho, K. Jung, K. Cho, J.-W. Kwark, Y. J. Kim, B.-S. Kim, Determination of the optimal span length to minimize resonance effects in bridges on high-speed lines, Proceedings of the Institution of Mechanical Engineers, Part F: Journal of Rail and Rapid Transit (2014) 1-10.

[19] G. Mylonakis, G. Gazetas, Seismic soil-structure interaction: beneficial or detrimental?, Journal of Earthquake Engineering 04 (03) (2000) 277 301. doi:http://dx.doi.org/10.1142/S1363246900000175.

URL http://www.worldscientific.com/doi/abs/10.1142/ S1363246900000175

[20] E. Kausel, Early history of soil-structure interaction, Soil Dynamics and Earthquake Engineering 30 (9) (2010) 822 - 832, special Issue in honour of Prof. Anestis Veletsos. doi:http://dx.doi.org/10.1016/j.soildyn.2009.11.001.

URL http://www.sciencedirect.com/science/article/pii/ S0267726109001754

21] M. Ülker Kaustell, R. Karoumi, C. Pacoste, Simplified analysis of the dynamic soil-structure interaction of a portal frame railway bridge, Engineering Structures 32 (11) (2010) 3692 - 3698 doi:http://dx.doi.org/10.1016/j.engstruct.2010.08.013.

URL http://www.sciencedirect.com/science/article/pii/ S0141029610003020

[22] A. Romero, P. Galvín, J. Domínguez, Comportamiento dinámico de viaductos cortos considerando la interacción vehículo-víaestructura-suelo, Revista Internacional de Métodos Numéricos para Cálculo y Diseño en Ingeniería 28 (1) (2012) 55 - 63. doi:http://dx.doi.org/10.1016/j.rimni.2011.11.004.

URL http://www.sciencedirect.com/science/article/pii/ S0213131511000381

[23] A. Romero, M. Solís, J. Domínguez, P. Galvín, Soil-structure interaction in resonant railway bridges, Soil Dynamics and Earthquake Engineering 47 (2013) 108 - 116, sI: José Manuel Roësset. doi:http://dx.doi.org/10.1016/j.soildyn.2012.07.014.

URL http://www.sciencedirect.com/science/article/pii/ S0267726112001716

[24] S. Ju, Determination of scoured bridge natural frequencies with soil-structure interaction, Soil Dynamics and Earthquake Engineering 55 (2013) 247 - 254. doi:http://dx.doi.org/10.1016/j.soildyn.2013.09.015. URL http://www.sciencedirect.com/science/article/pii/ S0267726113002017

[25] E. Moliner, Dynamic behaviour of high-speed railway bridges and its retrofit with passive viscoelastic dampers, Ph.D. thesis, Departamento de Ingeniería de la Construcción y Proyectos de Ingeniería Civil, Universidad Politécnica de Valencia (2012 (in Spanish)).

[26] L. Frýba, Dynamics of Railway Bridges, Thomas Telford, 1996.

[27] S. L. Grassie, R. W. Gregory, D. Harrison, K. L. Johnson, The dynamic response of railway track to high frequency vertical excitation, Journal of Mechanical Engineering Science 24 (2) (1982) 77-90. arXiv:http://jms.sagepub.com/content/24/2/77.full.pdf+html, doi:10.1243/JMES_JOUR_1982_024_016_02. URL http: //jms . sagepub. com/content/24/2/77. abstract

[28] C. Rebelo, L. S. da Silva, C. Rigueiro, M. Pircher, Dynamic behaviour of twin single-span ballasted railway viaducts - field measurements and modal identification, Engineering Structures 30 (9) (2008) 2460 - 2469

[29] T. Rauert, H. Bigelow, B. Hoffmeister, M. Feldmann, On the prediction of the interaction effect caused by continuous ballast on filler beam railway bridges by experimentally supported numerical studies, Engineering Structures 32 (12) (2010) 3981 - 3988.

[30] C. Rigueiro, C. Rebelo, L. S. da Silva, Influence of ballast models in the dynamic response of railway viaducts, Journal of Sound and Vibration 329 (15) (2010) 3030 - 3040.

[31] W. Zhai, S. Wang, N. Zhang, M. Gao, H. Xia, C. Cai, C. Zhao, High-speed train-track-bridge dynamic interactions - part ii: experimental validation and engineering application, International Journal of Rail Transportation 1 (1-2) (2013) 25-41. arXiv:http://dx.doi.org/10.1080/23248378.2013.791497, doi:10.1080/23248378.2013.791497.

URL http: //dx.doi .org/10.1080/23248378.2013.791497

[32] W. Zhai, H. Xia, C. Cai, M. Gao, X. Li, X. Guo, N. Zhang, K. Wang, High-speed train-track-bridge dynamic interactions - part i: theoretical model and numerical simulation, International Journal of Rail Transportation 1 (1-2) (2013) 324. arXiv:http://dx.doi.org/10.1080/23248378.2013.791498, doi:10.1080/23248378.2013.791498

URL http://dx.doi .org/10.1080/23248378.2013.791498

[33] A. Doménech, P. Museros, M. Martínez-Rodrigo, Influence of the vehicle model on the prediction of the maximum bending response of simply-supported bridges under high-speed railway traffic, Engineering Structures 72 (2014) 123 - 139 . doi:http://dx.doi.org/10.1016/j.engstruct.2014.04.037.

[34] T. Arvidsson, R. Karoumi, Train-bridge interaction - a review and discussion of key model parameters, International Journal of Rail Transportation 2 (3) (2014) 147186. arXiv:http://dx.doi.org/10.1080/23248378.2014.897790, doi:10.1080/23248378.2014.897790

URL http://dx.doi .org/10.1080/23248378.2014.897790

[35] G. Kouroussis, D. Connolly, O. Verlinden, Railway-induced ground vibrations - a review of vehicle effects, International Journal of Rail Transportation 2 (2) (2014) 69110. arXiv:http://dx.doi.org/10.1080/23248378.2014.897791, doi:10.1080/23248378.2014.897791. URL http: //dx .doi .org/10.1080/23248378.2014.897791

[36] M. Martínez-Rodrigo, J. Lavado, P. Museros, Dynamic performance of existing high-speed railway bridges under resonant conditions retrofitted with fluid viscous dampers, Engineering Structures 32 (2010) 808-828.

[37] S. Erhan, M. Dicleli, Effect of dynamic soil-bridge interaction modeling assumptions on the calculated seismic response of integral bridges, Soil Dynamics and Earthquake Engineering 66 (2014) 42 - 55. doi:http://dx.doi.org/10.1016/j.soildyn.2014.06.033.

URL http://www.sciencedirect.com/science/article/pii/ S0267726114001572

[38] P. Galvín, A. Romero, A 3D time domain numerical model based on halfspace Green's function for soil-structure interaction analysis, Computational Mechanics 53 (2014) 1073-1085. doi:10.1007/s00466-013-09491

[39] M. Prabucki, O. von Estorff, Dynamic response in the time domain by coupled boundary and finite elements, Computational Mechanics 6 (1) (1990) 35-46.

[40] P. Galvín, A. Romero, A MATLAB toolbox for soil-structure interaction analysis with finite and boundary elements, Soil Dynamics and Earthquake Engineering 57 (2014) 10 - 14. doi:http://dx.doi.org/10.1016/j.soildyn.2013.10.009.

URL http://www.sciencedirect.com/science/article/pii/ S0267726113002261

[41] A. Romero, P. Galvín, J. Domínguez, 3D non-linear time domain FEM-BEM approach to soil-structure interaction problems, Engineering Analysis with Boundary Elements 37 (3) (2013) 501 - 512. doi:http://dx.doi.org/10.1016/j.enganabound.2013.01.001.

URL http://www.sciencedirect.com/science/article/pii/ S0955799713000052

[42] P. Galvín, A. Romero, J. Domínguez, Fully three-dimensional analysis of high-speed train-track-soil-structure dynamic interaction, Journal of Sound and Vibration 329 (24) (2010) 5147 - 5163. doi:http://dx.doi.org/10.1016/j.jsv.2010.06.016 
URL http://www.sciencedirect.com/science/article/pii/ S0022460X10004062

[43] O. Zienkiewicz, The finite element method, 3rd Edition, McGraw-Hill, 1986.

[44] N. Newmark, A method of computation for structural dynamics, ASCE Journal of the Engineering Mechanics Division 85 (1) (1959) 67-94.

[45] O. von Estorff, M. Prabucki, Dynamic response in the time domain by coupled boundary and finite elements, Computational Mechanics 6 (1) (1990) 35-46. doi:10.1007/BF00373797.

URL http://dx.doi .org/10.1007/BF00373797

[46] I. Karnovsky, O. Lebed, Formulas for structural dynamics, McGraw Hill, 2000.

[47] European Committee for Standardization EN 1991-2, Eurocode 1 - Actions on Structures - Part 2: Traffic loads on bridges, CEN, Brussels, 2002.

[48] American Association of State Highway and Transportation Officials, AASHTO LRFD Bridge Design Specifications, 2012.

[49] L. Auersch, Train induced ground vibrations: different amplitude-speed relations for two layered soils, Proceedings of the Institution of Mechanical Engineers, Part F: Journal of Rail and Rapid Transit 226 (5) (2012) 469-488. arXiv:http://pif.sagepub.com/content/226/5/469.full.pdf+html, doi:10.1177/0954409712437305.

URL http://pif . sagepub. com/content/226/5/469. abstract

[50] S. A. Badsar, M. Schevenels, W. Haegeman, G. Degrande, Determination of the material damping ratio in the soil from sasw tests using the half-power bandwidth method, Geophysical Journal International 182 (3) (2010) 1493-1508. doi:10.1111/j.1365-246X.2010.04690.x.

URL http: //dx.doi.org/10.1111/j.1365-246X.2010.04690.x

[51] P. A. Costa, R. Calçada, A. S. Cardoso, Track-ground vibrations induced by railway traffic: In-situ measurements and validation of a $2.5 \mathrm{~d}$ fem-bem model, Soil Dynamics and Earthquake Engineering 32 (1) (2012) 111 128. doi:http://dx.doi.org/10.1016/j.soildyn.2011.09.002.

URL http://www.sciencedirect.com/science/article/pii/ S0267726111002521

[52] G. Lombaert, G. Degrande, J. Kogut, S. François, The experimental validation of a numerical model for the prediction of railway induced vibrations, Journal of Sound and Vibration 297 (3-5) (2006) 512 - 535. doi:http://dx.doi.org/10.1016/j.jsv.2006.03.048.

URL http://www.sciencedirect.com/science/article/pii/ S0022460X06003178 